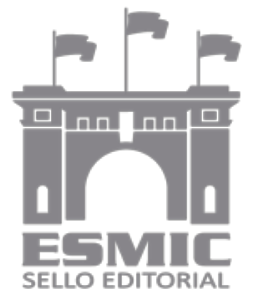

Revista Científica General José María Córdova

ISSN 1900-6586 (impreso), 2500-7645 (en línea)

Volumen 16, Número 22, abril-junio 2018, pp. 163-186

http://dx.doi.org/10.21830/19006586.326

Citación: Romero León, H. (2018, abril-junio). Teorías de la verdad y mundo contable: de la correspondencia a la estrategia comunicativa. Rev. Cient. Gen. José María Córdova, 16 (22), 163-186. DOI: http://dx.doi.org/10.21830/19006586.326

\title{
Teorías de la verdad y mundo contable: de la correspondencia a la estrategia comunicativa
}

Sección: Historia

Artículo de investigación científica y tecnológica

\author{
Henry Antonio Romero León * \\ Universidad Central, Bogotá, Colombia
}

\begin{abstract}
Theories of truth and the accounting world: from correspondence to communicative strategy

Teorias da verdade e o mundo contábil: da correspondência à estratégia comunicativa

Théories de la vérité et le monde comptable: de la correspondance à la stratégie communicative
\end{abstract}

Recibido: 12 de junio de 2016 • Aceptado: 14 de marzo de 2018

* https://orcid.org/ 0000-0001-8631-1173 - Contacto: hromerol@ucentral.edu.co 
Resumen. En este escrito se busca proponer una lectura sobre la representación y la verdad en la contabilidad desde la teoría discursiva de Jürgen Habermas. Esto ha de permitir una mejor comprensión de la naturaleza comunicativa implicada en la divulgación de información financiera y la emisión de estándares para su difusión. Mediante un breve repaso sobre las teorías filosóficas de la verdad, se hace una revisión crítica a las observaciones hechas por algunos tratadistas contables al respecto. Así, se introducen los conceptos de "giro pragmático" y «acto de comunicación» en la información contable, como constructo heurístico que hace posible hacer una aclaración conceptual necesaria para el desarrollo teórico y práctico. Si se considera la contabilidad como acto comunicativo, se desestructura la idea de ser abordada en términos de simple información. En consecuencia, se sostiene que su validez no solamente radica en la verdad, sino en la veracidad y la corrección normativa.

Palabras clave: acción comunicativa; correspondencia; información financiera; pragmatismo; representación; realidad; validez; verdad.

Abstract. This paper proposes a reading on the representation and truth in accounting from the discursive theory of Jürgen Habermas, which should enable a better understanding of the communicative nature involved in the disclosure of financial information and the issuance of standards for its dissemination. After a brief review of the philosophical theories of truth, a critical review is made of the observations in this regard by some accounting writers. Thus, the concepts of "pragmatic turn" and "communicative action" are introduced into the accounting information, as a heuristic construct that makes it possible to make a conceptual clarification, necessary for theoretical and practical development. If accounting is considered a communicative action, the idea of it being approached as mere information is undone. Consequently, it is argued that its validity not only lies in the truth, but in normative veracity and correction.

Keywords: communicative action; correspondence; financial information; pragmatism; reality; representation; truth; validity.

Resumo. Este artigo procura propor uma leitura sobre representação e verdade em contabilidade a partir da teoria discursiva de Jürgen Habermas. Isso deve permitir um melhor entendimento da natureza comunicativa envolvida na divulgação de informaçôes financeiras e na emissão de padróes para sua disseminação. Através de uma breve revisão das teorias filosóficas da verdade, faz-se uma revisão crítica das observaçôes feitas por alguns escritores contábeis a esse respeito. Assim, os conceitos de "giro pragmático" e "ação comunicativa" são introduzidos na informação contábil, como um construto heurístico que possibilita uma clarificação conceitual necessária ao desenvolvimento teórico e prático. Se a contabilidade é considerada como um ato comunicativo, a ideia de ser abordado em termos de informaçōes simples é desestruturada. Consequentemente, argumenta-se que sua validade não reside só na verdade, mas sim na veracidade e correção normativa.

Palavras-chave: ação comunicativa; correspondência; informação financeira; pragmatismo; realidade; representação; validade; verdade.

Résumé. Cet article propose une lecture sur la représentation et la vérité en comptabilité à partir de la théorie discursive de Jürgen Habermas. Cela devrait permettre une meilleure compréhension du caractère communicatif de la divulgation de l'information financière et de la publication de normes pour sa diffusion. À travers une brève revue des théories philosophiques de la vérité, une revue critique est faite des observations faites par certains auteurs comptables à cet égard. Ainsi, les notions de «tournent pragmatique» et «l'agir communicationnel» sont introduites dans l'information comptable, comme une construction heuristique qui permet d'apporter une clarification conceptuelle nécessaire au développement théorique et pratique. Si la comptabilité est considérée comme un acte de communication, l'idée d'être approché en termes d'information simple est décomposée. Par conséquent, on soutient que sa validité ne réside pas seulement dans la vérité, mais dans la véracité et la correction normative.

Mots-clés : action de communication ; correspondance; information financière ; pragmatisme ; réalité ; représentation ; validité ; vérité. 


\section{Introducción ${ }^{1}$}

Dada la condición actual de la contabilidad en la sociedad y en el conocimiento, su definición ha presentado algunas dificultades, pero parece estar ya muy decantada a partir del giro pragmático, tras la estandarización contable en los Estados Unidos en los años setentas. Sería normal considerar que las afirmaciones contables emanadas de la información se pueden demostrar de manera ostensiva en su mayoría y, por tanto, la verdad de ellas tiene una configuración aceptable, sobre la base de las versiones de la verdad que se identifican como de correspondencia. En igual sentido, las afirmaciones sobre la realidad económica que se hacen por medio de la contabilidad, al ser sistemáticas tienen un grado de coherencia importante. El presentar tal grado también las dota de y define su verdad, pero esta vez desde un enfoque coherentista. Esta forma de ver la verdad se designará aquí como «visión epistemológica».

De otro lado la contabilidad como discurso estratégico, además de ser un producto que circula en la sociedad entre agentes interesados para sus decisiones racionales, adquiere un sentido teleológico con repercusiones en la vida cotidiana de los actores en el mundo financiero y contable. Sus atributos de verdad se desplazan a un nivel de reconocimiento y legitimación de la información contable con carácter no epistemológico, es decir a un ángulo de practicidad y utilidad. Esta segunda aproximación se denominará «visión pragmática».

Tanto en los negocios como en los propios órganos emisores ${ }^{2}$ de normas para la elaboración de información financiera, los estándares mismos y la información financiera,

1 En el artículo "El valor razonable y la conexión perdida entre contabilidad y auditoría" (Jeppsen \& van Liempd, 2015), publicado aquí en un número anterior, los autores daneses propusieron un ejercicio reflexivo sobre las conexiones entre el paradigma contable y el paradigma de la auditoria, considerando que la búsqueda de la verdad en el primero ha condicionado la práctica de la segunda, para luego analizar el establecimiento del valor razonable como criterio intersubjetivo. La observación principal que los autores aducen es que, aun cuando en la contabilidad se ha intentado colegir un tipo de verdad con matices consensualistas desde presupuestos teóricos habermaseanos, la auditoría se ha mantenido en los márgenes de la representación y la búsqueda de la verdad objetiva. El presente artículo se elaboró en el curso del año 2015, razón por la cual en la revisión no se alcanzó a incluir la postura de Jeppsen \& van Liempd. Esta nota aclaratoria se hace con la intención de precisar que, si bien hay una coincidencia importante en el marco teórico con el texto en mención, nuestra propuesta no tiene la misma intención y el mismo alcance. Desde mi punto de vista me ubico en un plano general con respecto a la contabilidad y la información financiera y no abordo directamente la práctica de la auditoría. La contabilidad es interpretada a la luz de las teorías de la verdad no solo de Habermas sino de las ideas formuladas por Rorty y Davidson al respecto. En ese sentido, puede haber un complemento. Por otro lado, considero que no solo son actos de habla los que se profieren en la contabilidad financiera y en la auditoria, sino que son auténticos actos de comunicación, lo que dista significativamente de la perspectiva adoptada por Jeppsen \& van Liempd, y tiene implicaciones analíticas mayores que considerarlos como actos de habla tout court. Del mismo modo, al sostener que hay una reorientación hacia la verdad consensual en la contabilidad, en la información financiera y en la práctica de auditoría, no sostengo que necesariamente se tenga que dar una construcción social de consenso, pues hay momentos en que ni la contabilidad ni la auditoría buscan esto. Es decir, nuestros profesionales operan sobre consensos, mas no pretenden construir consensos. A lo sumo, el auditor llega a realizar un acto ilocucionario que no exige compromiso con lo que revisa ni convencimiento alguno.

2 Son las instituciones que emiten las normas que regulan la elaboración de estados financieros y reportes financieros. Actualmente las más importantes son el International Accounting Standard Board (IASB) en el ámbito mundial, y el Financial Accounting Standard Board en los Estados Unidos (FASB). 
requieren de un reconocimiento por parte de la comunidad de usuarios. Este reconocimiento se da en términos de legalidad por el procedimiento seguido en su elaboración (estándar oficial) y ético por la confianza pública que la sociedad tiene frente al trabajo que realizan los contadores públicos. Sin embargo, lo anterior no es un reconocimiento en términos de una verdad fundada en alguna de sus versiones. Esto nos pone de entrada en la problemática que supera la visión epistemológica y da un salto hacia una explicación pragmática. En este sentido, la pregunta consiste en la utilidad de la discusión filosófica alrededor de la verdad para la disciplina contable y asimismo para la información financiera en su función tecnológico-social. De antemano, puede decirse que tiene grandes repercusiones en el campo de la práctica contable, porque en la acción es en donde la contabilidad adquiere su significado social y se configura como un acto comunicativo auténtico.

\section{Teorías de la verdad como correspondencia}

Existe una explicación sobre la verdad fundada en la creencia que lo que es verdadero, es decir, la verdad de una proposición "consiste en su acuerdo (o correspondencia) con la realidad [...] posiblemente podríamos usar para los mismos fines, la oración siguiente: una oración es verdadera si designa un estado de cosas existente." (Tarski, 1944/2012, p. 61). Esta definición se basa en la idea de representación, la cual depende de la dualidad mente - mundo. Semejante definición opera también bajo el supuesto de que en la mente se representa lo que es el mundo, y representar de manera correcta el mundo en la mente es lo verdadero (Davidson, 2003). Del mismo modo, sirve para caracterizar el realismo, ya que sus defensores parten de que la realidad es independiente del sujeto.

La correspondencia es una forma de entender la verdad no solo con fines descriptivos sobre la realidad física, sino que por tal cosa se entiende cualquier afirmación que se sostenga como verdadera y corresponda con lo que son los hechos. Sin embargo, hay críticas que no se pueden desconocer, como esta proferida por Rorty: "nada figura como justificación a no ser por referencia a lo que aceptamos ya, y que no hay forma de salir de nuestras creencias y de nuestro lenguaje para encontrar alguna prueba que no sea la coherencia." (Rorty, 1978/1995, p. 168). El punto de esta crítica es que la única forma de confrontar representación lingüística y mundo sería salirnos de nuestra propia condición de usuarios de una lengua natural y confrontarlos, pero esto no es posible. Por tanto, lo único que se puede hacer es ver si la coherencia que tales proposiciones tienen, armoniza con lo que ya creemos y consideramos verdadero o, lo que es lo mismo, ser plenamente conscientes de que "lo que no podemos hacer es elevarnos por encima de todas las comunidades humanas, reales y posibles. No podemos encontrar un asidero celestial que nos eleve desde nuestra mera coherencia - mero consenso- a algo como «la correspondencia» con la realidad tal cual es en sí misma” (Rorty, 1996, p. 61). 


\section{La teoría coherentista de la verdad y del significado}

La respuesta de Davidson (1990/2012) parte de que "el concepto de verdad tiene conexiones esenciales con los conceptos de creencia y significado" (p. 208). Esto en la medida en que las creencias "son estados de personas que tienen intenciones, deseos y órganos sensoriales; son estados causados por acontecimientos internos y externos a los cuerpos de quienes las tienen, y que a su vez causan tales acontecimientos." (Davidson, 2003, p. 195). Las creencias son estados que las personas tienen en su relación e interacción con el mundo interno y externo, tanto físico como social. Las creencias son causadas por tal relación. Además de esto, la coherencia de las creencias es un criterio importante para configurar el concepto de verdad en Davidson. La orientación hacía la coherencia es clara, pero no hay un abandono de la idea de correspondencia. A la par resulta evidente que "no todo conjunto consistente de oraciones interpretadas contiene solo oraciones verdaderas, puesto que un conjunto así podría contener solo la oración consistente $s$ y otro solo la negación de $s$, y añadir más oraciones, a la vez que se mantiene la consistencia, no sirve de nada. Podríamos imaginar un sinfín de descripciones de estado — descripciones máximamente consistentes - que no describen nuestro mundo." (Davidson, 2003, p. 194)

A pesar de esto, la propuesta se desplaza hacia la coherencia como criterio para la verdad sin recurrir a la confrontación entre enunciados y realidad. En esta vía, la coherencia se presenta como un criterio para juzgar la verdad de un conjunto de creencias que sostiene una persona y, según Davidson (2003), depende de dos cosas: "de lo que significan las palabras tal como han sido dichas y de cómo está dispuesto el mundo.” (p. 196). Así, la estructura comunicacional humana cobra importancia y es allí donde el intérprete evidencia la necesidad de comprender el significado del hablante y, a su vez, lo que este cree para que la comunicación y el entendimiento sean efectivos. Lo fundamental radica en la manera en que el hablante pretende ser interpretado, pero la comunicación también se conduce de acuerdo con la interpretación real que hace luego su interlocutor (Davidson, 2012, p. 227). Por otra parte, como fenómeno social, para Davidson la interpretación tendría una base mínima de racionalidad:

La posibilidad de entender el habla o las acciones de un agente depende de la existencia de un patrón fundamentalmente racional, un patrón que debe, en líneas generales, ser compartido por todas las criaturas racionales. No tenemos más elección, entonces que proyectar nuestra propia lógica sobre el lenguaje y las creencias de otro." (Davidson, 2012, p. 236).

Este escenario muestra que para comprender a otro se requiere de un elemento común, de que tanto hablante e interprete sean racionales. De este modo, para que avance la interpretación de significado y verdad se debe poner no solo atención a las relaciones lógicas de las afirmaciones proferidas que hace el hablante, sino que además se requiere observar los objetos y eventos del mundo que causan que las considere verdaderas, en el 
marco, de la intención supuesta, de que el hablante espera ser interpretado solo de cierta manera (Davidson, 2012). Si esto es así — se pregunta Davidson- ¿cómo se confirma la verdad de una de una secuencia oracional? La clara ubicación del lenguaje como un fenómeno social permite suponer que "la interpretación correcta del habla de una persona por otra debe en principio ser posible" (Davidson, 2012). Y lo será, si se apoya en evidencia disponible y accesible públicamente, en conductas del hablante fácilmente observables de donde se inferirán las condiciones de verdad y el significado intencional, no como cuestión de suerte, sino como consecuencia de la propia constitución del lenguaje.

\section{Teorías pragmatistas de la verdad}

\section{Enfoque norteamericano}

En el pragmatismo, Rorty, Davidson y Dewey "concuerdan en que debemos dejar a un lado la idea de que el conocimiento es el intento de representar la realidad. Deberíamos, en cambio, visualizar la indagación como un modo de usar la realidad." (Rorty, 2012, pág. 575). Este giro pragmático en la explicación de la verdad representa un salto importante en la discusión, y sugiere un uso de la realidad para la consecución de propósitos. En este enfoque se entabla una relación entre el uso que le damos a la realidad y la verdad, pues la verdad no es una propiedad del mundo, lo es de las afirmaciones hechas mediante el lenguaje y de las creencias que se sostienen.

\section{Enfoque Consensual - Discursivo}

Tanto Habermas (2002) como Apel (1991) y (2003/2012) sostienen que la verdad como consenso no pretende dar una explicación de la realidad como lo puede ser la teoría de la correspondencia, sino que busca el establecimiento de las normas para la acción moralmente correcta. Con esta declaración, la verdad desde la perspectiva discursiva da un paso adelante y se redimensiona a la luz del uso del lenguaje, para destacar que este no se usa solo con un fin descriptivo de la realidad, sino que tiene usos distintos como el evaluativo y el prescriptivo.

En este orden se toma como eje la idea de actos de habla (Searle, 1969/1990), en los cuales no solo describimos estados de cosas, sino que se puede dar una orden, hacer un compromiso, una declaración o una expresión, es decir se tiene un sentido en lo que se dice. Tiene simultáneamente una fuerza generadora de intersubjetividad (Fabra, 2008) derivada de la distinción hecha por Austin del acto lucucionario e ilocucionario (Austin, 1962/1982), es decir que no solo es acto en cuanto se dice algo de algo (contenido proposicional), o se define por el modo en que esto se dice (es decir, en su sentido particular) o por la forma como se quiere que dicho acto sea entendido. De este modo Habermas (1989) sostiene que:

Podemos decir que un acto de habla se logra cuando entre hablante y oyente se establece una relación, y por cierto la relación pretendida por el hablante, y cuando el oyente 
puede entender y aceptar el contenido emitido por el hablante en el sentido que viene indicado en el propio acto de habla, p. e. como una promesa, como una afirmación, como un consejo. (p. 334)

Tener éxito en la comunicación para Habermas exige que haya un entendimiento no solo proposicional, sino también del sentido en que se dice. A partir de la propuesta de Austin (1962/1982) los actos de habla se ven también como perlocucionarios que pretenden que lo que el hablante dice tenga un efecto en el oyente y además lo induzca a actuar sobre esa base. Esta panorámica es la que lleva a Habermas (1989), por un lado, a reconocer la relevancia de los actos de habla para fines prácticos $\mathrm{y}$, por otro, a exponer lo que él llama las pretensiones de validez que se dan en la comunicación, que configuran tanto actos de habla como el acuerdo que de fondo existe en cualquier juego de lenguaje. A este respecto Habermas (1989) señala que:

En la intención comunicativa del hablante esta (a) ejecutar una acción correcta por relación al contexto normativo dado, para que pueda establecerse entre él y el oyente una relación interpersonal reconocida como legítima; (b) hacer un enunciado verdadero (o proposiciones de existencia pertinentes), para que el oyente pueda aceptar y compartir el saber del hablante; y (c) manifestar verazmente sus opiniones, intenciones, sentimientos, deseos, etc., para que el oyente pueda dar credibilidad a lo dicho. (p. 501)

Estas pretensiones son las que hacen que la comunicación sea efectiva y pueda servir para la consecución de acuerdos intersubjetivos con fines prácticos. En síntesis, se puede afirmar que cuando hablamos con alguien tenemos pretensiones con el solo hecho de establecer la comunicación. En otras palabras, decimos algo que consideramos es verdadero en el mundo, reconocemos y estamos dispuestos a actuar y actuamos siguiendo unas normas, además de ser veraces o sinceros con lo que decimos.

La teoría discursiva de la verdad representa un giro importante en la forma de entender la verdad desde una perspectiva pragmática, centrándose en la comunicación como acto con fines de entendimiento y consenso racional. Por tanto, la verdad deja de ser exclusivamente un asunto de referencia al mundo objetivo, para avanzar en la justificación a través de razones sobre la corrección normativa socialmente reconocida y sobre la justificación a través de razones sobre las motivaciones subjetivas de las personas cuando se comunican. En este orden no se niega la correspondencia, pero si se rechaza el reduccionismo a la misma.

La verdad entra a formar parte de una pretensión dentro de la comunicación, que en conjunto con la corrección normativa y la veracidad conforman una categoría superior como lo es la validez. El argumento fundamental a este respecto es que, en la comunicación, así como para la verdad de los enunciados no tenemos acceso directo a las condiciones que lo hacen verdadero. Asimismo, en la corrección normativa no se tiene una instancia externa para medir su corrección, pues en la comunicación quedamos sometidos a las condiciones de aceptabilidad racional, las que hacen que los oyentes puedan tomar 
postura con un «sí» frente a la pretensión que tiene el hablante como «otro». Es decir, que las condiciones de aceptabilidad racional conducen a un reconocimiento intersubjetivo y un acuerdo sobre contenidos con miras a una interacción posterior mediante el uso de argumentos en el discurso. (Habermas, 1981/1999).

Es clara la distinción que se hace frente a las pretensiones de validez en cuanto a verdad y corrección normativa. Una ventaja como bien se sostiene es que contamos con el mundo para desmentir esa pretensión de verdad y volverla una simple justificación aquí y ahora o simplemente mostrarse como falsa. Lo característico acá es que se recurre a algo por fuera de la propia justificación argumentativa para afirmarlo o desmentirlo. En el caso de la corrección normativa, al no existir esa explicación ontológica, se procede a comprender que si los afectados

llegan conjuntamente, mediante discursos prácticos, a la convicción de que un determinado modo de actuar es igualmente bueno para todas las personas, entonces considerarían esta práctica como vinculante. El consenso alcanzado discursivamente tiene para los participantes algo de definitivo. No constata ningún hecho, sino que «fundamenta» una norma; una norma cuya «existencia» no radica en otra cosa que en «merecer» reconocimiento intersubjetivo. (Habermas, 2002, p. 284)

Para Habermas, la corrección de juicios morales se obtendría por la misma vía que nos permite llegar a la verdad concertada, ya que su pretensión de verdad o validez se fundaría siempre en un proceso de argumentación al ser imposible para nosotros tener acceso a las normas de su reconocimiento universal, así como tampoco somos capaces de acceder a las condiciones de verdad de forma directa. (Habermas, 2002, p. 273). Por tanto, es en este plano común entre pretensiones de validez que, tanto enunciados descriptivos como juicios morales, se examinan a la luz de las condiciones de aceptabilidad racional.

El desplazamiento hacia un terreno discursivo, pone la verdad, la corrección normativa y la veracidad como objetos susceptibles de justificación argumentativa. Lo cual quiere decir que se juzga ya no a través de las condiciones de verdad, sino por medio de las condiciones de aceptabilidad racional bajo condiciones ideales discursivas. Desde la perspectiva de Habermas, tales condiciones pueden entenderse como base de una pragmática universal, que si bien no tiene el carácter incondicional de la verdad como tradicionalmente se entiende, sí constituye una especie de prerrequisito universal sobre el que es posible llegar a un entendimiento acerca del mundo objetivo, el mundo subjetivo y el mundo social.

\section{Sobre la verdad en la contabilidad}

El punto de partida para examinar la problemática de la verdad y partiendo del denominado giro pragmático, recae en la pregunta de hasta qué punto es relevante la discusión sobre la verdad para la vida práctica (Rorty, 2007). En el caso de este estudio, 
debemos formularla con mayor precisión: ¿es importante la verdad para la comunidad, la práctica y el pensamiento tal como se efectúa en el campo contable y adelantar su estandarización?

Por un lado, y a manera de hipótesis, podría decirse que sí es relevante en la medida que los actores en el mundo financiero requieren bases confiables para fundamentar las decisiones, pero la confianza puesta en las proposiciones y oraciones derivadas de la información no necesariamente se basan en alguna teoría sobre la verdad. Esta es más bien una confianza en los expertos y en los estándares empleados que aquella asentada en una postura directa frente a la verdad, una postura que emana de la practicidad y la efectividad que por tradición reporta lo que se ha hecho siempre: las reglas, las convenciones y las formas de racionalidad que el mundo de los negocios exige para su funcionamiento. La pregunta entonces ahora se formularía en términos de en qué radica y qué naturaleza tiene esa confianza. Esta pregunta puede ser muy bien respondida con las palabras que Gerboth una vez escribió: "la racionalidad y la objetividad en la contabilidad dependen sobre todo de la racionalidad y la objetividad de las personas quienes la practican ... [y de] las personas encargadas del papel de normalizadores". (1987, p. 6, citado por Shapiro, 1997). En este sentido la confianza radica en que hay un lenguaje convencional común, unas reglas y una racionalidad compartida, aun cuando en el curso de los acontecimientos del mundo financiero, esto ha resultado insuficiente.

Por otro lado, la pregunta no resultaría relevante, porque no parece ser un asunto demasiado importante para preparadores y usuarios, ni tampoco para los normalizadores, pues en las discusiones sobre estándares es poca la referencia a estas cuestiones y además se consideran marginales. No ocurre así con los académicos de la contabilidad, que sí han explorado de manera importante el problema de la realidad, la representación y la verdad en el mundo contable, desde diferentes bases conceptuales filosóficas. Pero que a pesar de estos importantes ejercicios se quedan como discusiones académicas especializadas y con marginal efecto en la comunidad contable en la forma de comprender la contabilidad como disciplina científica, su alcance, naturaleza y potencial.

El debate que se ha dado en algunos círculos académicos se desprende del análisis que hace Thomas Lee (2006), al tratar aspectos centrales de la contabilidad y de los organismos de estandarización contable. Por esta razón partiré de dicho debate.

El valor del ejercicio que hace Lee sobre consiste en que logra llevar la discusión de lo enteramente epistemológico a la estandarización. En todo caso, no es el primero en tratar el tema, pues en la literatura encontramos otros intentos previos como el de Cowan (1965) quien hace la comparación del enfoque británico de verdad e imparcialidad (truth and fairness) con el enfoque norteamericano, centrado en la presentación fiel, la aceptación generalizada y la consistencia (fair presentation, general acceptance and consistency).

Antes de entrar a examinar su postura, quisiera precisar que Lee basa su interpretación en el Marco Conceptual del año 2005 y sus versiones anteriores. Creo oportuno en primer lugar, traer algunos elementos que en el marco conceptual de IASB - FASB del 
año 2010 y en el borrador del año 2015, para mostrar que hay una preocupación en estos organismos emisores de normas contables relativa a los compromisos frente a la realidad $y$, en consecuencia, en referencia al alcance de la contabilidad y la información que a partir de ella se puede producir.

El marco conceptual del año 2010 producto de la convergencia entre FASB e IASB, resalta que

en gran medida, los informes financieros se basan en estimaciones, juicios y modelos en lugar de representaciones exactas. El Marco Conceptual establece los conceptos que subyacen en esas estimaciones, juicios y modelos. Los conceptos son las metas que se esfuerzan en alcanzar el Consejo y los preparadores de los informes financieros. Como en la mayoría de las metas, la visión del Marco Conceptual de la información financiera ideal es improbable que se alcance en su totalidad, al menos no a corto plazo, porque lleva tiempo comprender, aceptar e implementar nuevas formas de analizar transacciones y otros sucesos. (IFRS Foundation, 2010).

Esta declaración evidencia una preocupación por el tema de la representación de la realidad y, por ende, advierte el problema de la naturaleza de la representación. Adviértase el sentido casi preventivo con el que se enfrenta la representación, es decir, la precaución de no comprometerse con la exactitud de los fenómenos, dejando un margen de parcialidad en el tiempo y la dependencia de las metas que se persiguen con la información. De lo cual se infiere que instituciones como la IASB-FASB hacen una salvedad que evade, en primer lugar, la definición y explicación de la realidad a la que, en segundo lugar, se refiere la contabilidad durante el proceso de comunicación por el que se realiza, e incluso evita la representación contable misma. Este es el punto de la crítica adelantada por Lee, la cual sigue teniendo vigencia.

La precisión en el uso de los conceptos y de las metas de la contabilidad y de la información contable producida, salvan parcialmente el enfoque de IASB-FASB de la crítica ya citada. La sugerencia que resulta es si el enfoque de la representación fiel de los fenómenos económicos implica necesariamente un compromiso con alguna teoría de la verdad, en especial con la teoría de la correspondencia. Si bien podemos adjudicar un compromiso ontológico del marco conceptual, ello no lleva a que se desprenda un compromiso con alguna teoría de la verdad en particular. Aquí solo podría estar apelándose al sentido común y esa es la razón por la cual no hay mayor profundización y explicación al respecto. De cualquier manera, interpretar que hay una concepción de la verdad latente en el enfoque del IASB-FASB, no es alejado de lo que en el trasfondo hay. No apelar de forma explícita a una teoría de la verdad o explicarla no quiere decir que no se tenga.

La crítica se puede resumir como sigue, de acuerdo con FASB (1980):

la fiabilidad en la contabilidad depende de la representación fiel que significa la correspondencia entre una medición y un recurso económico u obligación (o cambios en los mismos). En ninguna parte de esta definición jerárquica hay discusión o explicación de 
la realidad social que se mide, fenómeno, recurso económico, u obligación económica. Por esta razón, este escrito concluye que, si el FASB continúa haciendo caso omiso o siendo inconsciente del significado filosófico de la realidad social y de la verdad como correspondencia con respecto a la representación contable, PBAS fallaría en mejorar la información financiera corporativa. A lo sumo, se convierte en otro ejercicio de legitimación profesional para la comunidad contable- es decir, el razonamiento de sentido común provee confort y seguridad en los contadores públicos y en sus servicios. (Lee, 2006, pág. 3)

Al examinar esta declaración de conceptos de FASB del año 1980 encontramos que, como bien lo analiza Lee, se precisa que la fiabilidad descanse sobre la representación fiel, la cual se define en términos de "la correspondencia o acuerdo entre los números contables y los recursos o eventos que esos números se proponen representar" (FASB, 1980). En esta declaración se usa el concepto de correspondencia, pero no se sabe si es un razonamiento de sentido común o si hay un compromiso filosófico con la teoría de la correspondencia. Si revisamos el marco conceptual del año 2010 y el borrador de 2015, podemos encontrar que la "información financiera representa fenómenos económicos en palabras y números [...] la representación fiel no quiere decir exactitud en todos los aspectos. [...] En gran medida, los informes financieros se basan en estimaciones, juicios y modelos en lugar de representaciones exactas." (IFRS Foundation, 2010)

Hay un giro importante en la concepción que tiene FASB - IASB. A esta concepción la podríamos llamar precautoria en el mejor sentido de Rorty (2007). Sin embargo, no hay una explicación y profundización al respecto. Al sostener que las representaciones no son exactas, hace pensar que hay una precaución frente a lo definitivo que puede ser sostener una correspondencia con la realidad. Por otro lado, la referencia a "fenómenos" sí que conlleva un compromiso con la metafísica, en tanto puede implicar noúmenos (pensamientos); o bien, con la corriente fenomenológica, lo cual es más plausible. Esto último sí reflejaría un cambio importante en la dirección que Lee y otros autores como Mattessich, Mouck y Macintosh han sugerido.

Ahora bien, nos parece que no resulta justificada la demanda de Lee a la FASB. Antes hay que ver si eso es atinente a los propósitos de un organismo de estandarización. Desde una perspectiva pragmatista, la regulación contable en los años setenta abandonó la tarea de buscar una verdad o buscar principios universales para la práctica contable. El hecho que se haya entendido la contabilidad como un producto de la sociedad desde una perspectiva funcionalista y teleológica, es muestra suficiente para que se asuma que la justificación filosófica alrededor de la realidad se salga de las prioridades de un órgano de estandarización. Lo que no significa que dicha justificación no se haga desde los frentes académicos, pues las reflexiones allí generadas serán una base para nuevas reglamentaciones sobre la práctica de preparación de información financiera. 


\section{De la correspondencia a la interpretación radical y triangullación semántica en la contabilidad}

¿Cómo entender la verdad como correspondencia en la contabilidad? Desde la perspectiva semántica de la verdad, la contabilidad puede pretender hacer referencia a objetos del mundo físico, pero el lenguaje que emplea la contabilidad no está plenamente determinado y diferenciado. En todo caso, como mínimo podríamos llegar a construir un lenguaje formal que posibilitara hacer todas las proposiciones contables y las relaciones que se puedan establecer entre ellas. Un intento que hizo en su momento Mattessich (1962/2002) al proponer una axiomatización por medio de un lenguaje formal. Sin embargo, esta y otras propuestas se centraron en formalizar el procedimiento contable, más que en constituir un lenguaje a partir del cual se pudiera juzgar lo verdadero o no verdadero de alguna proposición contable sobre la realidad.

La correspondencia es inevitable pero no puede tomarse de manera reduccionista. El lenguaje no solo se usa de manera descriptiva ya que sus usos son múltiples. Lo que hace de la verdad como correspondencia solo un caso entre esa multiplicidad. Por esta razón las críticas hacia la representación de la realidad en la contabilidad, no se resuelven solo comprendiendo que la realidad es una construcción social, sino que debe orientarse a avanzar en la multiplicidad de usos del lenguaje. Este aspecto fue puesto en evidencia por John Searle (1969/1990).

Un avance importante y que sea apropiado para comprender la contabilidad y la información financiera, debe pasar por la propuesta coherentista inicialmente hecha por Davidson (2003). La verdad, creencia y significado tienen una conexión, así que al ser creencias sobre lo que se juzga como verdad. Todas las personas (llámense estas preparadores y usuarios de la información y en la contabilidad), en su relación con el mundo natural y social, buscan sostener conjuntos de creencias causadas por esa relación, que sean coherentes entre sí.

Esto es un punto de partida fundamental para comprender que la verdad en la contabilidad puede ser bien determinada y estar bien explicada. En primer lugar, Davidson propone una suerte de sustitución de la confrontación entre creencia y realidad, producto de la noción verdad como correspondencia, por el criterio de coherencia. Así las cosas, la coherencia de las creencias ayuda a definir la verdad. Este primer argumento es básico en cualquier conjunto de creencias, y suponemos que a pesar de la forma como se vienen construyendo los estándares de información financiera, existe un buen grado de coherencia entre lo que se cree en la contabilidad y lo que creen las personas alrededor de la información financiera. Sin embargo, es oportuno precisar que, así como Davidson lo sugiere, la sola coherencia no produce la verdad, aun cuando sea un criterio objetivo de verdad.

Porque, según el argumento davidsoneano, podríamos tener un conjunto coherente de criterios contables y, en consecuencia, una información financiera coherente, pero ello simplemente no nos diría nada acerca del mundo o de la realidad de los hechos. Por esta 
razón, la verdad en la contabilidad y en la información depende de lo que significan las palabras con que se expresan socialmente y la forma como esté dispuesto el mundo (en el caso considerado, los hechos, los fenómenos económicos que se pretenden mostrar).

De esta forma, la correspondencia no se elimina del todo, pero si avanzamos en que la verdad también radica en la coherencia de las creencias y no solo radica en lo que es el mundo. Esto resultará evidente, porque se presume que cualquier persona por lo general sostiene un conjunto de creencias que considera verdaderas, y pensar lo contrario (es decir, que las personas sostienen conjuntos de creencias falsas o contrarias al conocimiento en general, y a partir de ello llegan a configurar su vida y su actuar), es un sinsentido.

Tomando en cuenta que, cuando alguien dice algo, quiere significar con ello algo de sus creencias sobre lo que es el mundo, sobre lo que es la realidad económica de una entidad, y es así que los hablantes esperan que sus intérpretes les crean lo que están afirmando. De este modo la creencia, la significación, la coherencia y lo que es el mundo, son expuestos en una experiencia de comunicación, en la que se configura una triangulación semántica, en donde el intérprete de un hablante logra conocer el significado de sus afirmaciones. Porque esto parte de un principio de caridad, es decir, dotar al hablante de coherencia en lo que cree y dice, así como de referencia al mundo, las mismas a las que está expuesto el intérprete. Aquí tenemos una condición compartida, la cual posibilita que el intérprete conozca el significado de lo que el hablante dice, pues a través de sus reacciones a los estímulos, el intérprete logra correlacionarlas con los estímulos del mundo (Davidson, 2003).

Este paso hacia la comunicación hace que pensemos, durante el proceso de transmisión de signos producido con la preparación y divulgación de información financiera, en la existencia de una creencia común, tanto en el intérprete como en el hablante, sobre el fenómeno económico o la realidad económica. El mencionado principio de caridad es el que hace posible que haya un entendimiento y una confianza por parte del intérprete (usuario) frente al hablante (preparador y evaluador). La circunstancia no parece demasiado distinta y configura una triangulación, pues el intérprete proyecta una racionalidad económica en el hablante, una referencia al mundo y una coherencia en sus afirmaciones proferidas, del mismo modo en que aparecen los estándares emitidos por IASB y FASB. Asimismo, en este conjunto de creencias se presume que, si se sostienen, es porque son verdaderas, y al tener coherencia en su conjunto y en su mayoría serían verdaderas. En ¿qué medida cabría duda en ello? Esta pregunta nos conduce a una dimensión mayor que es la que abordaremos en lo que sigue.

La configuración del proceso de generar información financiera y evaluaciones de auditoría, tal como se desprende de la cotidianidad, es propiamente una acción realizada a través del lenguaje. Por tanto, al convertirse en un acto de comunicación, tiene un significado con el cual se pretende haya entendimiento por parte un hablante que se dirige hacia un oyente. 
Las observaciones que hace McKernan (2007) con respecto a la objetividad de la contabilidad en reacción a Shapiro haciendo uso de las ideas de Davidson muestran que, si bien tenemos la limitación del lenguaje para conocer y expresar el mundo, esto no quiere decir, como bien afirma Davidson, que no se pueda hablar de objetividad y en nuestro caso de objetividad en la contabilidad.

McKernan (2007) trae a colación, tres acepciones de lenguaje que son fundamentales y recurrentes en círculos académicos. Afirma que por un lado, la contabilidad como lenguaje puede ser un medio transparente que simplemente muestra las cosas como ellas son. Por otro lado, sostiene que la contabilidad como lenguaje puede concebirse como un medio semitransparente o translúcido que es capaz de dar luz, pero con algún nivel de distorsión o difusamente. Finalmente, indica que la contabilidad puede ser vista como un lenguaje que sirve para expresar las construcciones que sobre la realidad hacemos, en tanto es un medio denso que no permite ver el mundo como es, sino que los objetos son construidos dentro de nuestros esquemas conceptuales. Los tres modos de comprender la contabilidad como lenguaje parten de presupuestos ontológicos y epistemológicos específicos que son los que permiten comprender la contabilidad en uno u otro sentido.

El punto central de la crítica de McKernan es que, con apoyo de Davidson, ninguna de estas tres acepciones resiste un escrutinio. Hay que precisar lo siguiente: cuando Davidson expone su idea de la interpretación radical, presenta un escenario donde un hablante y un intérprete se hallan y el recurso del intérprete es entender el significado de las afirmaciones proferidas por los hablantes, dado que ambos emplean lenguajes distintos. En primer término, en la comunicación contable no es necesaria una interpretación radical porque los miembros de la comunidad están inmersos y permeados por el medio en que actúan. Por tanto, su lenguaje es compartido. En segundo lugar, el llamado principio de caridad que Davidson defiende para la triangulación semántica no se requiere, en tanto que el intérprete y el hablante gozan de una comunidad en ello. A modo de simulación, el ejercicio del auditor puede bien coincidir con una suerte de interpretación sobre lo que el preparador de la información ha querido afirmar en la información financiera. Pero sólo de una manera muy marginal cabría esta aplicación, porque tanto auditor como contador emplean las mismas bases normativas para preparar y evaluar. De ahí que difícilmente podamos hacer coincidir tal escenario financiero con una interpretación radical al estilo Davidson.

Si se tratará de una interpretación de algún sistema contable surgido en un contexto muy distinto, ya sea en el espacio o en el tiempo, la estructura conceptual davidsoniana sería de importancia capital para hacer una interpretación de dicho sistema contable, pero esto no es explícito en McKernan.

Lo que sí es valioso en la propuesta de McKernan es el haber insistido en la idea de comenzar a entender que con la contabilidad vista como acto comunicativo, nuestra percepción no entra en los juegos de interpretación sobre la información financiera, sino que está mediada por el lenguaje. La idea de percepción proposicional de Davidson no 
solo es válida para el uso de los lenguajes naturales y los lenguajes especializados como el de la ciencia, sino que resulta del todo adecuado y aplicable para las disciplinas de conocimiento como la contabilidad. En efecto, en todos estos casos, el significado y la verdad dependerían de esas percepciones proposicionales, esto es, de saber cómo es el mundo a través del lenguaje. No tiene el usuario de la información, o el intérprete, otra alternativa viable que actualizar sus percepciones a través de las proposiciones y comprender el significado que el hablante quiere significar. En esto radica el entendimiento y utilidad de la información.

De ahí que la verdad se debería examinar en dos instancias: primero, en el plano del preparador de información que pretende una representación fiel, dimensión «representacionalista» en la que el auditor se ve inmerso en tanto verificador y examinador; y, segundo, la verdad que considera el usuario de la información al recibir dicha información en calidad de receptor de proposiciones coherentes sobre cómo es el mundo, cómo es la realidad de la entidad que informa, y al que no le queda más camino que la percepción proposicional, con todo lo que esta puede implicar.

Así las cosas, la interpretación la hace el intérprete sobre lo que observa del hablante, el mundo a partir de un esquema conceptual propio, es decir, en términos de lo subjetivo, lo objetivo y lo intersubjetivo. Por tanto, lo objetivo en la información financiera que puede observar el intérprete, está determinado por su percepción proposicional. Pero esto no necesariamente conduce a hacer una interpretación adecuada de lo que el hablante quiso significar, pues además necesita observar la información que es de acceso público para encontrar tanto el significado como la verdad en las proposiciones contables. Lo subjetivo radica en saber que se está teniendo un pensamiento sobre algo en el mundo, saber que lo informado significa algo del mundo objetivo. Lo intersubjetivo ha de entenderse como la racionalidad y los esquemas que hacen que haya entendimiento de lo que el emisor afirma y que asimismo concedo en el principio de caridad. Solo así es posible una interpretación en la comunicación financiera.

La idea del esquema conceptual en Davidson cumple un papel importante que puede servir para hacer precisión sobre la interpretación radical y la triangulación en el mundo contable. Y con esto se quiere terminar esta sección. Los esquemas conceptuales a los que se recurre para justificar posturas relativistas, en general para Davidson (2003), no son sustentables. En realidad, es un extremismo pensar que haya esquemas conceptuales que nos hagan vivir en mundos diferentes cuando justamente estamos compartiendo un mundo físico, un espacio y un tiempo, así como la información la que públicamente tenemos acceso. El argumento relativista de los esquemas conceptuales y la inconmensurabilidad de estos, fácilmente se cae por el acceso público al mundo a través del lenguaje. Lo que sí es destacable de la interpretación que hace McKernan de Davidson es que no por tener esquemas conceptuales distintos habitamos mundos distintos. Y la información que refiere a ello se torna relativa ya sea a intereses o a relaciones con el mundo y la realidad. Porque si hay algo que refleja la información financiera y supone de entrada para 
prepararse y presentarse de la manera como se hace, es por el hecho de que hay un mundo compartido, una sociedad configurada por relaciones capitalistas, valores y principios que determinan el accionar de los agentes en este tipo de sociedades. Por tanto, las diferencias basadas en esquemas conceptuales realmente no tienen asidero en la forma como epistemológica, ontológica y socialmente se entiende la contabilidad financiera, pues siempre se ha concebido dentro del mismo esquema conceptual general: el mundo del lenguaje humano y su historia.

\section{Contabilidad y verdad discursiva: el auténtico giro pragmático de la contabilidad}

Es preciso a comprender que la verdad depende en gran medida de la efectividad que produzca en la acción y el sentido universalista que Habermas (1989) nos sugiere. Los compromisos ontológicos y epistemológicos para la contabilidad deben estar completamente claros e identificados para poder ser útil en su función tecnológica, es decir, en la conformación de información de carácter financiero útil en la toma de decisiones económicas.

La relación con la verdad se media por la efectividad en cómo nos desenvolvemos en el mundo. La contabilidad, ha girado hacia posturas pragmatistas en sentido propio y estructurado desde el Informe Trueblood inspirado en la Asobat. Los fines se vuelven relevantes para la estandarización, los usuarios y sus necesidades en la configuración de los objetivos de la información. Así la estructura pragmática emerge dentro del ya latente paradigma de la utilidad de la información heredado de los años treinta del siglo XX. La relación racional e instrumental entre los medios y los fines en la emisión de estándares y en la consecuente preparación de información, refleja el espíritu pragmatista tal como lo ha descrito bien Mattessich (1995) y (2003a). Este avance promete llevar a la contabilidad a un nivel mayor. No es exagerado pensar que los niveles de coherencia, resultado de los avances formalizadores realizados en los años sesenta del pasado siglo, demuestran una madurez en la estructuración de la contabilidad y los estándares.

El pragmatismo norteamericano no solo es una visión filosófica, sino que se manifiesta en las más diversas actividades científicas y políticas. Del mismo modo, la actividad contable en los citados años sesentas refleja dicho espíritu. Además de esto, podemos pensar en si es suficiente con tal enfoque de la verdad para la contabilidad. Sin duda alguna hay que comenzar a examinar los efectos que tiene la verdad en las acciones y en la vida de las personas, pues se vuelve en extremo pertinente. Este análisis no sería completo, sin la ayuda de la propuesta del pragmatismo que surge de la comunicación.

Partamos de la idea de que la contabilidad y la información contable son un acto comunicativo, y que como tal no solo emplea el lenguaje para describir el mundo, sino que, como lo han señalado Austin (1962/1982), Searle (1969/1990) y Habermas (1981/1999, 1989), también el lenguaje serviría para declarar, prometer, ordenar, etc. En especial, 
debemos pensar que la información financiera es un acto locucionario, ilocucionario y perlocucionario. De tal modo que se busca decir algo, que además es susceptible de ser entendido y que tiene un efecto en los usuarios. Lo anterior, en el mismo sentido que la emisión de estándares por IASB - FASB puede examinarse a la luz del uso del lenguaje con fines de entendimiento y con fines de llegar a un acuerdo. Para aclararlo es preciso hacer algunas precisiones en lo que sigue.

La teoría discursiva de la verdad parte del concepto de acto de habla que introduce el filósofo John Searle. Esto representa el primer reto para esta discusión y justificación del avance que se busca plantear. En esencia la pregunta es: ¿cómo es posible entender el proceso de la información contable como un auténtico acto de habla? Al respecto puede servirnos esta reflexión de Searle:

La unidad de la comunicación lingüística no es como se ha supuesto generalmente, el símbolo, la palabra, oración, ni tan siquiera la instancia del símbolo, palabra u oración, sino más bien la producción o emisión del símbolo, la palabra u oración al realizar el acto de habla. Considerar una instancia como un mensaje es considerarla como una instancia producida o emitida. Más precisamente, la producción o emisión de una oración-instancia bajo ciertas condiciones constituye un acto de habla, y los actos de habla [...] son las unidades básicas o mínimas de la comunicación lingüística. (1969/1990, p. 26)

Con la información financiera que se produce a través de la contabilidad y demás informes de auditoría independiente, se está realizando un acto de habla en tanto se está diciendo algo sobre la realidad con la intención de afirmar algo. Según las características cualitativas de dicha información tal producción de información representa fielmente los fenómenos económicos. Igualmente con ellos se promete que se pagarán, cobrarán, distribuirán, etc., recursos económicos (activos y pasivos) y se promete que seguirá operando en el futuro (negocio en marcha). Base sobre la cual se reconocen los hechos presentes cuyos efectos financieros serán futuros. Además, con los informes de auditoría independiente se declara la razonabilidad, representación fiel, relevancia, etc. de la información. Por otro lado, el intérprete, oyente o usuario, comparte y concede al hablante emisor, unas reglas para el lenguaje que está empleando, así como una racionalidad. Solo así logra su entendimiento.

$\mathrm{Al}$ emitirse información se hace un acto de decir algo (locución), sino que se espera que el intérprete, oyente (usuario) entienda (ilocución) lo que se dice, entienda las razones que ha tenido el hablante para expresar lo que expresa en la información. Asimismo, con el acto el emisor busca tener un efecto en la acción del interprete (perlocución) para la toma de decisiones. Si esto constituye un acto de habla en sentido estricto, podemos avanzar en la concepción de la verdad que propone la teoría discursiva y las implicaciones que esto trae. 
Según Habermas, un acto de habla se logra cuando entre el hablante y el oyente se establece una relación, el tipo de relación que se busca al informar al usuario, quien entenderá y aceptará el contenido y el sentido que se espera (como se diría en lenguaje técnico contable en los aspectos de relevancia e importancia relativa) mediante una afirmación, una promesa o un consejo.

En estas condiciones de la comunicación, y sobre la base de que el lenguaje no solo se usa para describir estados de cosas u objetos, tenemos la necesidad de hacer un desplazamiento de la verdad propio de este uso particular del lenguaje, hacia las instancias normativas y morales.

En un primer momento, la verdad discursiva nos lleva a reconocer que resulta relevante para la comunicación contable financiera una concepción en términos «representacionalistas», o de correspondencia, en donde podamos afirmar algo como verdadero y se pueda aceptar sobre la base de su existencia y de lo que es el caso (los hechos u objetos). Pero, en un segundo momento, también nos permite considerar que las acciones de preparación de la información y la definición de las reglas y estándares contables por parte de los organismos responsables, deben ser ejecutadas de manera correcta sobre la base de un contexto normativo para que esa relación producida en el acto sea legítima y aceptada. Además, la condición final de la acción comunicativa es la veracidad o sinceridad de las opiniones, sentimientos, e intenciones del hablante y el oyente.

Nuestra atención en la contabilidad se debe centrar en el mundo objetivo, en el subjetivo y en el intersubjetivo. Así, podemos sostener que, al convertirse la emisión de información financiera en un acto comunicativo, la verdad que subyace a ella y el trasfondo en el que se da, exigen un marco de referencia teórico y pragmático de la acción comunicativa. Esta idea trasciende la verdad como correspondencia y hace que se ubique con mayor precisión la discusión en lo que Habermas define como las pretensiones de validez en la comunicación, como ya se ilustró más arriba.

En esta dirección, la verdad de las proposiciones en la comunicación financiera no se puede omitir, y siempre estará presente. De hecho, las mediciones de los fenómenos que se reconocen en la información no son totalmente exactas, como bien lo puede declarar IASB-FASB en su marco conceptual, y que puede definirse como un enfoque cautelar sobre el alcance de las afirmaciones y proposiciones contables, en el sentido de Rorty (2007). Además, ello permite indicar que las proposiciones contables incorporan un proceso de medición, el cual es objeto de decisión y cuya estimación hace que la verdad se vuelve aún más imprecisa. Sin embargo, y en esto se debe reconocer la intensión de IASB-FASB, es posible ver aquí un avance, dado que con la cualidad de verificabilidad se busca también la objetividad, porque

ayuda a asegurar a los usuarios que la información representa fielmente los fenómenos económicos que pretende representar. Verificabilidad significa que observadores independientes diferentes debidamente informados podrían alcanzar un acuerdo, aunque 
no necesariamente completo, de que una descripción particular es una representación fiel. La información cuantificada no necesita ser una estimación única para ser verificable. (IFRS Foundation, 2010)

En igual sentido, la corrección normativa que el acto debe demostrar es la base para un entendimiento en la comunicación. Exige el reconocimiento por parte de los participantes, y en esto entra a jugar un tercer actor que, en el caso de la información financiera, es el emisor de las normas, pues es quien define luego de un procedimiento cuáles son las normas en que se debe producir el acto comunicativo. Los denominados estándares hacen las veces del contexto normativo específico que permea la acción comunicativa. Esta corrección normativa es insuficiente dada la particularidad del origen de la normatividad contable. Las características de esta normativa están concebidas dentro de una racionalidad teleológica, la que Habermas (2002) define como la racionalidad que permite una acción exitosa en función de una elección deliberada de medios para la consecución de un fin. Por su parte, esto exige que el agente sabe por qué ha tenido éxito y está motivado por tal saber, así como que es capaz de explicar por qué tiene éxito.

Este tipo de racionalidad es la base de la articulación del marco conceptual IASB FASB, en tanto la información se pretende producir con unos medios y unos atributos que permitan lograr su propósito. El acto comunicativo y en especial la corrección normativa, no obedece a una racionalidad teleológica, sino que debe partir de la base de una racionalidad comunicativa para lograr el entendimiento, debido a que la información financiera no es un acto individual, en cuyo caso bastaría con una racionalidad teleológica. En este sentido, para que el acto comunicativo tenga éxito requiere de una aceptación común de la norma. O lo que es lo mismo que la norma sea legítima, y esto se logra a través de la aceptación por las buenas razones implicadas que hacen los participantes de un juego de lenguaje como lo es la contabilidad. Estas buenas razones se desprenden directamente de las pretensiones de validez.

Es oportuno aclarar que el acto comunicativo y las pretensiones de validez no buscan en sí mismas la verdad, sino crear condiciones de entendimiento válido intersubjetivo sobre la base del mejor argumento. El resultado será un acuerdo, o por lo menos la puesta en discusión argumentativa y discursiva de los asuntos de relevancia para la comunidad contable. El problema que algunos vislumbrarán es el siguiente: si el propósito es una discusión argumentada con miras a establecer un consenso, ¿es posible aplicar esto al acto comunicativo de la información financiera tal como se ha definido? Aquí se concibe no en sentido laxo, lo cual sería improcedente, pues en el mencionado acto lo que pretende la información financiera es que sea entendida sobre las mismas bases y pueda tener un efecto en la acción (tomar una decisión económica, es decir, la primacía la tiene la racionalidad teleológica). Si esto es así, el acto de la información financiera es una acción comunicativa orientada al entendimiento, más no al acuerdo. A pesar de ello, sí parte de un acuerdo implícito en la comunicación que se deriva de que los actores dentro del mundo contable acepten de entrada las normas con las que se prepara la información financiera. 
En sentido propio la acción comunicativa orientada al acuerdo es una acción que es propia de los procesos de estandarización contable en los órganos encargados de dicha función, porque en este contexto el fin es obtener unas normas que puedan servir para mediar las relaciones intersubjetivas, en un mundo objetivo compartido por todos los interesados en la información, en las cuales y sobre el cual se pretende una acción racional. En este punto, es forzoso entender que la emisión de estándares de información financiera es un proceso en donde hay una acción teleológica y en grado marginal una acción comunicativa orientada al acuerdo, pues las decisiones de qué se aprueba y qué no, es imposible asentarlas en un consenso bastante homogéneo en intereses y no necesariamente recogen la fuerza del mejor argumento en la comunidad contable en general. La corrección normativa, como pretensión de validez, tiene dos instancias en el mundo contable: una en el proceso de emisión de las normas, dentro de un acto comunicativo orientado al acuerdo y, otra, en la aplicación de la norma financiera, producto del acuerdo, en la preparación de la información mediante un acto comunicativo orientado al entendimiento. Es en este orden de ideas Habermas (2002) dice que:

Si todos los posibles afectados, ante una materia necesitada de regulación, llegaran conjuntamente, mediante discursos prácticos, a la convicción que un determinado modo de actuar es igualmente bueno [útil] para todas las personas, entonces consideraría esta práctica como vinculante. El consenso alcanzado discursivamente tiene para los participantes algo de definitivo. No constata ningún hecho, sino que "fundamenta» una norma; una norma cuya «existencia» no radica en otra cosa que en «merecer» reconocimiento intersubjetivo; y los participantes parten de la base de que pueden precisamente comprobar esto bajo las condiciones cuasi ideales de un discurso racional. (p. 284)

Así las cosas, la legitimidad del estándar financiero dependería del reconocimiento de todos los afectados o de la forma como estos se vean reflejados o convencidos y dispuestos a acomodarse a la perspectiva de la generalidad y del procedimiento de legitimación empleado. Desde la perspectiva de Habermas (1985) esto sería el principio de universalización, que a través del discurso con las pretensiones de validez descritas se llegue a una aceptabilidad racional. Pero ¿qué tan dispuestos estarían IASB y FASB a aceptar estas bases de construcción normativa? Esta es una pregunta que se deriva como consecuencia de la que Lee hace sobre la correspondencia de la información y la idea de representación fiel. También es de la mayor relevancia, pues estamos frente al hecho de que, si la realidad es una construcción social, ¿cómo se está construyendo la realidad de la contabilidad y de las normas que la hacen funcional en la sociedad actual?

De este modo, se sigue el curso que va de las discusiones epistemológicas a las pragmático-políticas, en donde la ética del discurso puede aportar mucho, puesto que la construcción de la realidad social será el resultado de los discursos que como sociedad se logren justificar en el presente, pensando en públicos futuros sin pretensión de infalibilidad. La 
realidad económica a la que se dirige la contabilidad en la práctica, redefine siempre su configuración al tener que pasar por discursos pragmáticos, ético-políticos y morales.

Finalmente, la veracidad en lo que se dice, como la pretensión de validez que apunta a la subjetividad y a la sinceridad en los actos comunicativos, es superlativa en el mundo contable. Esta pretensión es determinante para que se pueda actuar sobre la base del acto comunicativo. No se busca con la información constatar un hecho, si este es verdadero en el sentido de una correspondencia. De lo que se trata más bien es de proceder con corrección normativa, sobre un conjunto de normas legítimo que exista solo por el reconocimiento que la comunidad de comunicación financiera reconozca intersubjetivamente. Aparte de esto, pretendemos sinceridad en el acto: la veracidad del hablante que, sin ella, desde el punto de vista del juego de lenguaje contable, la comunicación resultaría en fracaso. Y en este sentido, sí que podríamos corroborar el concepto de Harry Francfurt de "bullshit". La información financiera se convertiría en "bullshit", en charlatanería, cuando sus pretensiones de validez fallan, en especial la veracidad en el acto, pues si no hay sinceridad se tiene la intención de engańar y como dice Francfurt (2006) sería una forma de tergiversar e inducir a engaño.

\section{A modo de conclusión}

Reconocer que la verdad en contabilidad no es estática, como dicen los pragmatistas, y por el contrario ver que está vinculada con los intereses humanos, al ser cierta y verdadera por los acontecimientos y por sus efectos en la vida de las personas, resulta necesario para entender que la verdad desde el pragmatismo es fundamental para ayudar a ubicar el alcance epistemológico y funcional de la contabilidad en la sociedad.

La forma como se accede y acepta la verdad es indirecta a través de la argumentación discursiva, lo cual es algo paralelo al hecho de aceptar la corrección de las normas. Por tanto, verdad y corrección normativa se mueven en un mismo plano, en el plano del discurso argumentativo que pasa por las condiciones de aceptabilidad racional. De este modo, las preocupaciones de Lee (2006), Macintosh (2006), y Mattessich (2009) son insuficientes para explicar todo el asunto y no solo se enmarca en lo que Franco (2013) sostiene como subjetivismo y objetivismo;. La propuesta de Habermas nos lleva de un discurso centrado en la verdad a un discurso centrado en la validez y nos invita a "desepistemologizar» la discusión sobre la verdad.

Reconocer que el punto de partida en la contabilidad y en la información financiera es la comunicación, no ha sido suficiente. Pero comenzar a desestructurar el sentido del acto comunicativo de la información financiera, es apremiante para llegar a unas condiciones propicias para poder afirmar que la realidad es una construcción social y sobre todo que, como actores de ella, tenemos un papel en dicha construcción. Esto nos conduce a echar una mirada a los visos políticos que desde hace ya varias décadas pululan en la academia contable en el mundo. 


\section{Agradecimientos}

A la profesora Ángela Uribe Botero de la Universidad Nacional de Colombia por sus aportes en la redacción de gran parte de las secciones de este artículo.

\section{Declaración de divullgación}

Como autor del artículo manifiesto no tener ningún conflicto de interés en que se publique este artículo, el que está asociado a la línea de investigación Desarrollo, organizaciones y contabilidad del grupo de Investigación Ataralawaa Amaa, reconocido por Colciencias, del Departamento de Contaduría Pública de la Universidad Central.

\section{Financiamiento}

Este artículo ha sido resultado de un proyecto de investigación financiado en su totalidad con recursos internos de la Universidad Central durante el año 2016.

\section{Sobre el autor}

Henry Antonio Romero León es Contador Público y Magíster en Filosofía de la Universidad Nacional de Colombia. Está vinculado como docente de tiempo completo a la Universidad Central.

\section{Referencias}

Apel, K. O. (1991). Teoria de la verdad y ética del discurso. Barcelona: Paidós.

Apel, K. O. (2003/2012). Verdad como idea regulativa. En J. Nicolás, \& M. Frápolli, Teorías Contemporáneas de la Verdad (págs. 677-704). Madrid: Tecnos.

Austin, J. (1962/1982). Como hacer cosa con palabras. Barcelona: Paidós.

Baudrillard, J. (1978). Cultura y simulacro. Barcelona: Kairos.

Bayou, M., Reinstein, A., \& Williams, P. (2011). To tell the truth: A discussion of issues concerning truth and ethics in accounting. Accounting, Organizations and Society (36), 109-124.

Cowan, T. (octubre de 1965). Are Truth and Fairness Generally Acceptable? The Accounting Review, 788 - 794 .

Davidson, D. (1990/2012). Estructura y Contenido de la Verdad. En A. Nicolás, \& M. J. Frápolli, Teorias Contemporáneas de La verdad (págs. 189-247). Madrid: Tecnos.

Davidson, D. (2003). Subjetivo, Intersubjetivo, Objetivo. Madrid: Cátedra.

Davidson, D. (2012). Estructura y Contenido de la Verdad. En A. Nicolás, \& M. J. Frápolli, Teorias Contemporáneas de La verdad (págs. 189-247). Madrid: Tecnos.

Dewey, J. (1958). Experience and Nature. New York: Dover.

Fabra, P. (2008). Habermas: Lenguaje, Razon y Verdad. Madrid: Marcial Pons.

FASB. (septiembre de 2010). Statement Financial Accounting Concepts No. 8. SFAC No. 8. Norwalk, Connectucut. 
Financial Accounting Standard Board. (Mayo de 1980). Statement of Financial Accounting Concepts No. 2. Statement of Financial Accounting Concepts No. 2. Norwalk, Connectucut.

Franco, R. (2013). La polémica Macintosh-Mattessich. Revista científica "General José María Córdova”, 11(11), 209-226.

Frankurt, H. (2006). On Bullshit. Sobre la manipulacion de la Verdad. Barcelona: Paidós.

Habermas, J. (1972/2012). Teorías de la Verdad. En A. Nicolás, \& M. J. Frápoli, Teorías Contemporáneas de la Verdad. Madrid: Tecnos, pp. 625 - 675.

Habermas, J. (1981/1999). Teoria de la acción comunicativa I. Madrid: Taurus.

Habermas, J. (1985). Conciencia moral y accion comunicativa. Barcelona: Península.

Habermas, J. (1989). Teoría de la acción comunicativa: complementos y estudios previos. Madrid: Cátedra.

Habermas, J. (2001). Facticidad y Validez (3a. ed.). Madrid: Trotta.

Habermas, J. (2002). Verdad y Justificación. Madrid: Trotta.

Hendriksen, E. (1974). Teoría de la Contabilidad. México: UTHEA.

IFRS Foundation. (2010). Conceptual Framework for Financial Reporting. Conceptual Framework for Financial Reporting. London, United Kingdom.

James, W. (1906/2012). Concepcion de la verdad según el pragmatismo. En J. Nicolás, \& M. J. Frapoli, Teorías Contemporáneas de la Verdad (págs. 533-551). Madrid: Tecnos.

Jeppsen, K., \& van Liempd, D. (julio-diciembre de 2015). El valor razonable y la conexión perdida entre contabilidad y auditoría. Revista Científica General José María Córdova, 13(16), 135-171.

Lafont, C. (1998). Pluralism and Universalism in Discourse Ethics. London: Avebury Pres.

Lee, T. (2006). The FASB and Accounting for Economic Reality. Accounting and the Public Interest, pp. 1-21.

Macintosh, N. (2006). Accounting_Truth, Lies, or "Bullshit"?A Philosophical Investigation. Accounting and the Public Interest, 6, 22-36.

Mattessich, R. (1962/2002). Contabilidad y Métodos Analíticos. Buenos Aires: La Ley.

Mattessich, R. (1995). Critique of accounting. Westport: Quorum.

Mattessich, R. (2003). Accounting representation and the onion model of reality: A comparison of Baudrillard's orders of simulacra and his hyperreality. Accounting, Organizations and Society, 28(5), 443-470.

Mattessich, R. (2003a). Contabilidad: ¿cisma o síntesis? El desafío de la teoria condiconal normativa. Partida Doble (144), 104-119.

Mattessich, R. (2009). FASB and Social Reality - An Alternate Realist View. Accounting and the Public Interest, 39-64.

McKernan, J. (2007). Objectivity in accounting. Accounting organizations and Society (32), 155-180.

Moonitz, M. (1961). The basic postulates of accounting. Accounting Research Study No. 1. AICPA.

Mouck, T. (2004). Institutional reality, financial reporting and the rules of tha game. Accounting, Organizations and Society 29 (2004) 525-541(29), 525-541.

Rorty, R. (1978/1995). La filosofía y el espejo de la naturaleza. Madrid: Cátedra.

Rorty, R. (1996). Objetividad, Relativismo y Verdad. Barcelona: Paidós.

Rorty, R. (2007). Sobre la Verdad: ¿̨validez universal o justificación? Buenos Aires: Amorrortu. 
Rorty, R. (2012). La verdad sin correspondencia. En J. Nicolás, Teorías Contemporáneas de la Verdad (págs. 561-586). Madrid: Tecnos.

Rorty, R., \& Engel, P. (2007). What's the use of Truth? New York: Columbia University Press.

Ryan, B., Scapens, R., \& Theobald, M. (2004). Metodología de la Investigación en finanzas y contabilidad. Barcelona: Deusto.

Searle, J. (1969/1990). Actos de Habla. Madrid: Cátedra.

Searle, J. (1995). La construccion de la realidad Social. Madrid: Paidós.

Shapiro, B. (1997). Objetivity, Relativism and truth in external financial reporting: what's really at stake in the dispute? Accounting. organizations and society, 22(2), 165-185.

Sprouse, R., \& Moonitz, M. (1962). A tentative set of broad accounting principles for business enterprises. Accounting Research Study No. 2. AICPA.

Tarski, A. (1944/2012). La Concepcion semántica de la verdad y los fundamentos de la semántica. En A. Nicolás, \& M. J. Frápoli, Teorias Contemporáneas de la Verdad. Madrid: Tecnos, pp. 57 - 98.

Wittgenstein, L. (1921/2009). Tractaus Logico-philosophicus. Madrid: Gredos.

Wittgenstein, L. (1953/2009). Investigaciones Filosóficas. Madrid: Gredos. 